gated to the inaccessible interior of the plant, which thus presents an unrewarding woody exterior to herbivores. Divaricating plants also tend to have high nutrient content, as one would expect if divarication evolved to deter large herbivores of a sort absent elsewhere in the world and now extinct in New Zealand. What could those ghost herbivores be?
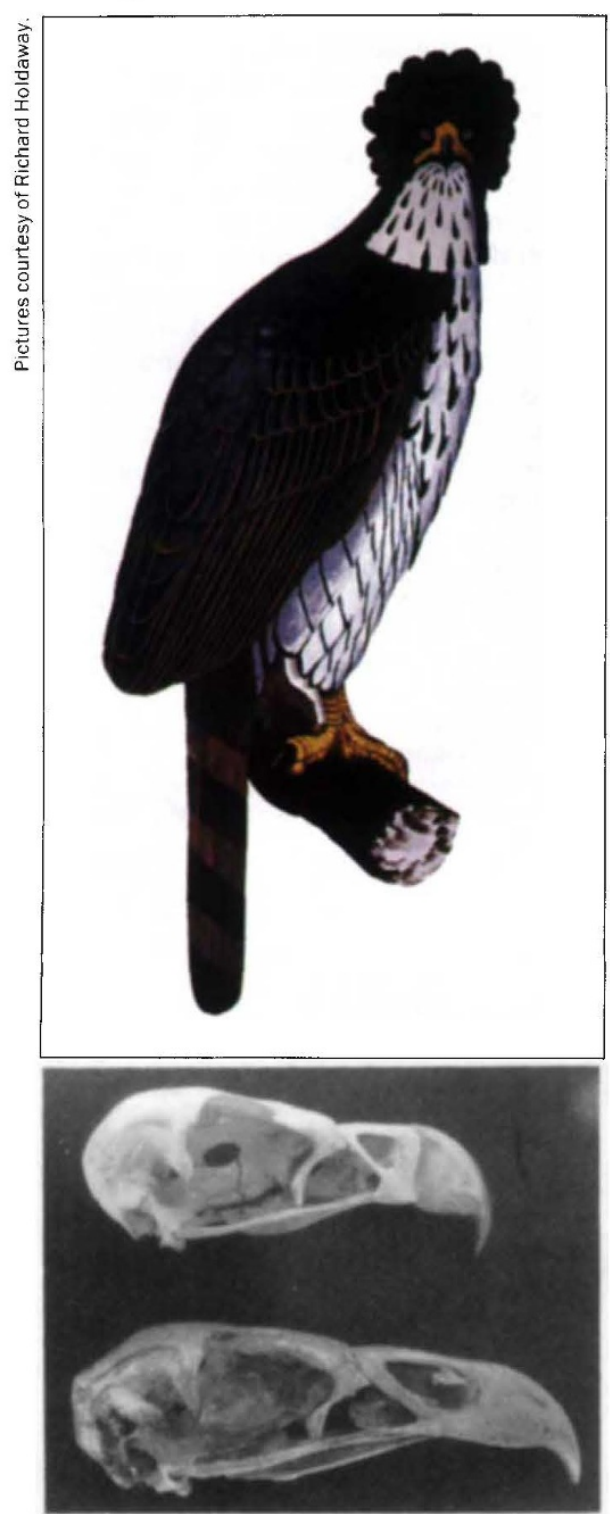

Giant predator - reconstruction of Haast's eagle (top) and its huge skull (bottom) compared to that of one of the world's largest living eagles, the wedge-tailed eagle of Australia.

Among the clues are the concentration of divaricating species on fertile alluvial soils and their absence or rarity among plants of cliffs, the alpine zone or canopy epiphytes. It is especially striking that several plant species that are divaricating on the New Zealand mainland are not so on offshore islands, and that nine species divaricating as juveniles cease to be so when they exceed about $3 \mathrm{~m}$ in height. As recognized by Atkinson and Greenwood $^{5.7}$, these clues strongly suggest that divarication evolved as a response to browsing by New Zealand's moas.

There were about 12 species of these giant, flightless, ostrich-like birds, all of which became extinct soon after arrival of Maoris 1,000 years ago. Preserved moa crops contain the remains of at least 38 plant species ${ }^{3}$. Weighing up to $200 \mathrm{~kg}$, moas could devour a plant at one bite and must have exerted a considerable selective force. Spines, the usual anti-herbivore device of plants exposed to soft-nosed mammalian browsers elsewhere in the world, would have offered little protection against the heavy, horny head-shields of moas, but divarication would tend to make plants uneconomic fodder.

Abundant fossils show that moas were concentrated on fertile alluvial soils, and were absent from offshore islands and rare in the alpine zone. Moas could not have climbed cliffs or into canopies of trees. The correlation between distribution of moas and of divarication is therefore good. The largest moas were about $3 \mathrm{~m}$ tall, nicely matching the height above which plants divaricating only as juveniles cease to be so as adults.

Similarly, among New Zealand's surviving bird species Holdaway ${ }^{2}$ has noted features known to function as antipredator devices elsewhere, despite the absence of large predators among surviving species native to New Zealand. Most of New Zealand's largest extant terrestrial birds kiwis, kakapo, kea and kaka - are nocturnal or cryptically coloured, or both. The ghosts responsible were two remarkable extinct predatory birds. One was a very large $(3 \mathrm{~kg})$ hawk originally described as a harrier but now recognized as the largest of the world's goshawks, a group of bird-hunting specialists. The other was the giant Haast's eagle, at up to $13 \mathrm{~kg}$ by far the world's largest predatory bird known from recent times. The eagle would have been the sole New Zealand predator capable of killing an adult moa. One can only speculate what this powerful specialist at attacking tall bipedal prey did when it saw the first arriving Maoris.

Unfortunately, introduced species such as deer and possums browse in ways very different from moas, just as introduced cats and dogs hunt differently from goshawks and eagles. Hence adaptations of New Zealand's plants and small vertebrates to ghosts of large birds failed to protect them against the onslaught of introduced mammals.

Jared $M$. Diamond is in the Department of Physiology, University of California Medical School, Los Angeles, California 90024, USA.

1. Caughley, G. N.Z. J. Ecol. 12 (suppl.), 3-10 (1989).

2. Holdaway, R.N. N.Z. J. Ecol. 12 (suppl.), 11-25 (1989)

Burrows, C.J.N.Z. J. Ecol. 12 (suppl.), 51-56 (1989)

Batchelor, C.L. N.Z. J. Ecol. 12 (suppl.) $57-65$ (1989)

4. Batchelor, C.L. N.Z. J. Ecol. 12 (suppl.) $57-65(1989)$. (suppt.), 67-96 (1989)

6. Janzen, D.H. \& Martin, P.S. Science 215, 19-27 (1989). 7. Greenwood, R.M. \& Atkinson, I.A.E. Proc. N.Z. ecol. Soc 24, 21-33 (1977)

\section{Bulk betrothal}

LAST week Daedalus presented Pairwise, a computer program for the mass arrangement of marriages. Pairwise pairs up a whole population of single individuals, each of whom has a set of 'bond-energies' representing his or her attraction towards each of the possible partners. It optimizes that pairing by iterative annealing. Partners are randomly exchanged between pairs while a fake 'temperature' is slowly reduced, inhibiting further disruption of the stablest established couples. The pairing that finally crystallizes out is thermodynamically stable. Everyone has done as well as possible; divorce and remarriage can never occur.

In today's divorce-ridden world, such mathematical help is sorely needed. Modern populations are socially so mobile that traditional methods of courtship can never examine enough partnerships to reach an optimum pairing. Despite the problem of deducing an individual's bond-energy profile from questionnaires, interviews and so on, Pairwise should be able to do much better. After all, it can marry off whole huge cohorts at a time!

At first, Daedalus will prudently retain several of his program's near-optimal solutions. Each client will be presented with (say) two partners, and an estimate that one of them is 90 per cent sure to be his or her best bet. Even this would eliminate a lot of marital disasters, and Pairwise should get better as its programmers gain experience. But ultimate perfection will always be elusive. One intriguing reason is that, while Pairwise anneals its solution down to an absolute zero, society always has a finite effective temperature. Random 'thermal dissociation' of apparently stable marriages can always happen; more energetic, less stable excited states of the assembly become accessible, and transitions between them can occur.

But what is temperature in this context? The social analogue of molecular energy, says Daedalus, the capacity to make things happen, is money and power. Marriage is at least partly an economic union, and individuals who acquire enough money can in effect buy their way out of it. Those who have power as well are certainly socially 'hotter' than the rest of us, and their relationships are always more labile - as borne out by a steady stream of sensational, highly publicized and expensive divorces. (Other top people, suspects Daedalus, enjoy more discreet forms of marital variety.)

So, says Daedalus, as a society gets hotter, and increasing riches and democracy give its people more power over their own lives, its divorce rate must rise. Strict moralists may prefer that cold political system that gives the people no money and no power - Marxism.

David Jones 